\title{
Supporting Information: Fiber-enhanced Raman gas spectroscopy for the study of microbial methanogenesis
}

Andreas Knebl ${ }^{1}$, Robert Domes ${ }^{1}$, Sebastian Wolf ${ }^{1}$, Christian Domes ${ }^{1}$, Juergen Popp ${ }^{1-3}$, and Torsten Frosch $^{1-3, *}$

${ }^{1}$ Leibniz Institute of Photonic Technology, 07745 Jena, Germany

${ }^{2}$ Friedrich Schiller University, Institute of Physical Chemistry, 07743 Jena, Germany

${ }^{3}$ Friedrich Schiller University, Abbe Center of Photonics, 07745 Jena, Germany

*Corresponding author: torsten.frosch@uni-jena.de, torsten.frosch@gmx.de

\section{Table of content}

Figure S1: Determination of $\mathrm{MeOH}$-content in $\mathrm{CH}_{4}$ containing air
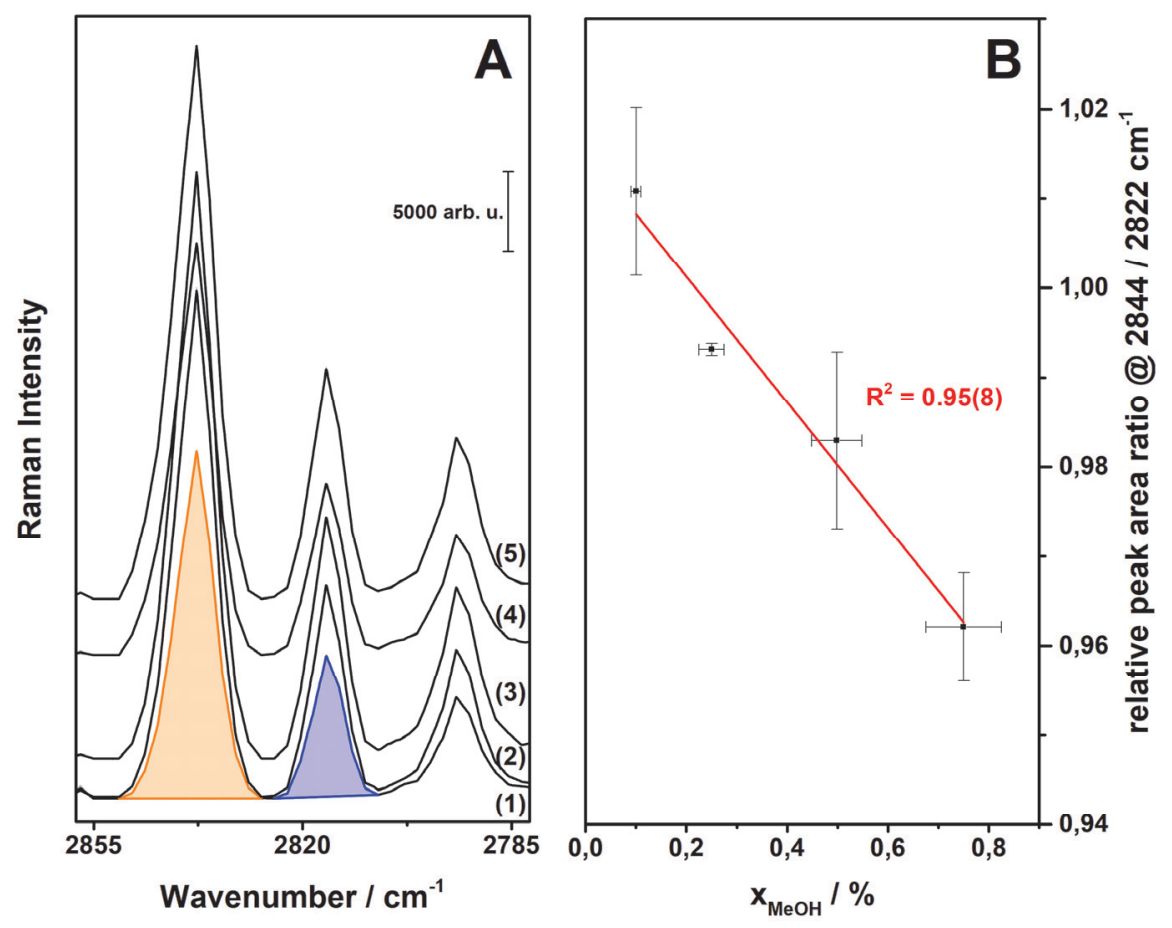

Figure S1: Determination of $\mathrm{MeOH}$-content in $\mathrm{CH} 4$ containing air. A O-band of the $\mathrm{V}_{3}$-vibration of $20 \%$ $\mathrm{CH}_{4}$ in the headspace of $\mathrm{MeOH}$-water mixtures $\left[x_{\mathrm{MeOH}}=0.00 \%(1), 0.10 \%(2), 0.25 \%(3), 0.50 \%\right.$ (4), and $0.75 \%$ (5)]. The O(9) peak of $\mathrm{CH}_{4}$ overlaps with the $\mathrm{CH}_{3}$ symmetric stretch peak of $\mathrm{MeOH}$ which leads to a defined broadening. $\mathrm{B}$ To quantify $\mathrm{MeOH}$ inside the $\mathrm{CH}_{4}$ signals, the peak area at $2844 \mathrm{~cm}^{-1}$ (orange) and at $2822 \mathrm{~cm}^{-1}$ (blue, corresponding to $\mathrm{V}_{3} \mathrm{O}(10)$ of $\mathrm{CH}_{4}$ ) are compared (see text) and a relative peak area ratio is calculated from the spectra in $\boldsymbol{A}$. The lower the relative peak area ratio, the larger the $\mathrm{MeOH}$ content. 